\title{
THE EFFECT OF SACHSENHAUSEN VISITORS' PERSONALITY AND EMOTIONS ON MEANING AND WORD OF MOUTH
}

\author{
JEROEN NAWIJN, MIRIAM BRÜGGEMANN, AND ONDREJ MITAS \\ NHTV Breda University of Applied Sciences, Academy for Tourism, Breda, \\ The Netherlands
}

\begin{abstract}
This study assessed the effect of visitors' personality and emotional response on finding positive meaning in life and the intention to spread positive word of mouth. The sample $(n=260)$ consists of visitors to Sachsenhausen Memorial and Museum near Berlin. Findings indicate that the emotion of interest positively contributes to finding positive meaning in life and positive word of mouth. The effects of personality are marginal. Personality explains little of the variance in positive meaning and positive word of mouth. Emotional response accounts for $25 \%$ of the variance in finding positive meaning in life-in terms of finding personal benefit from the visit, controlled for personality. Despite the dominant negative emotional response, tourists find positive meaning in their visit. These findings correspond with those observed in studies on personal trauma and loss. Positive meaning could potentially contribute to adjustment processes to cope with what occurred. Future research should include address longer term effects on postvisit behavior.
\end{abstract}

Key words: Emotions; Meaning in life; Dark tourism; Tourist experiences; Cultural heritage

Introduction

The study of emotional responses within tourism experiences is relatively new. Earlier work focused mostly on moods (e.g., Pearce, 1981) or adopted a more general approach of emotions in terms of positive and negative affect (e.g., Gilbert \& Abdullah, 2004; Nawijn, 2011). Psychologists emphasized that it is better to separate emotions from more general affective states (Lerner \& Keltner, 2000; Zeelenberg,
Nelissen, Breugelmans, \& Pieters, 2008) and to distinguish between specific emotions when studying a certain phenomenon (Mitas, Yarnal, Adams, \& Ram, 2012). Specific emotions have specific consequences in terms of behavior. For instance, feeling sad will have an effect on behavior that is different from an effect of feeling guilty. However, both these emotions are considered to be of negative valence. When only valence is studied, the distinction between different emotions of the same valence 
is lost, and consequently, potential effects in terms of behavior may be lost too. Although effects of emotions are studied extensively, this is not studied in a nonhedonic tourism context. The present study addresses this gap in research and studies the effects of emotions on positive word of mouth and meaning in life.

Studies on emotions in a tourism context focus almost completely on hedonically pleasant sites or trips (e.g., Bigné, Andreu, \& Gnoth, 2005; Hosany \& Gilbert, 2010; Nawijn \& Damen, 2014). Little is known about tourists' emotional response in nonhedonic tourism contexts. The nonhedonic context of this study is the former concentration camp of Sachsenhausen. Motives for tourists to visit former Nazi camps are not different from motivations found in regular heritage studies (cf. Biran, Poria, \& Oren, 2011; Isaac \& Çakmak, 2014). These motivations include educational motives, emotional involvement, identity formation and affirmation, connecting to one's own heritage, and seeking an authentic experience (Biran et al., 2011).

Studies that deal specifically with emotions at former Nazi camp sites are limited. As far as the authors are aware, there exists only one study that investigated the intensity of tourists' experience via a predetermined set of emotions. Nawijn and Fricke (2015) studied visitors to the Concentration Camp Memorial Neuengamme. Their study found that tourists feel negative emotions more intensely than positive emotions, which contrasts with emotional experience at hedonic sites (e.g., Lin, Kerstetter, Nawijn, \& Mitas, 2014). Although Nawijn and Fricke (2015) studied emotional response on-site, Nawijn, Isaac, Gridnevskiy, and Van Liempt (2015) studied expected emotional response and their study revealed that potential visitors to concentration camp memorials expect to feel a mix of positive and negative emotions. Emotional responses are mainly trigged by the direct environment, but tourists' emotions are also partly influenced by their personality (Lin et al., 2014). For instance, according to Lin et al. (2014), extraverted tourists experience less sadness and fear. These findings underpin the importance of studying personality and their relation to emotions in a tourism context.

The context of this study is the Sachsenhausen Memorial and Museum. Sachsenhausen is a former SS concentration camp located north of Berlin. Over
200,000 people were imprisoned at Sachsenhausen and an estimated 65,000 were killed (Farmer, 1995; Memorial and Museum Sachsenhausen, 2014). The Sachsenhausen concentration camp was built in 1936. In the early years, most prisoners were political opponents of National Socialism. From 1938 and onwards, other groups were imprisoned, such as Sinti and Roma, criminals, homosexuals, and Jews. In 1939 the camp began to include prisoners of war and people from occupied countries. By 1944, 90\% of the prisoners were non-Germans, mainly from the Soviet Union and Poland. The prisoners were used as forced laborers in the industry yard next to the camp. Prisoners could also be put into socalled punishment units, which were developed by the SS. Medical experiments were conducted on some of the prisoners. Evacuation of the camp was ordered on February 1, 1945, when it became clear that the Russian Red Army was approaching. Many prisoners were murdered in the industrial yard and during the evacuation of the subcamps. Others were deported to Mauthausen or Bergen-Belsen. Sachsenhausen was liberated on April 22, 1945, by Soviet and Polish troops (Memorial and Museum Sachsenhausen, 2014).

\section{Literature Review}

\section{Emotions}

Emotions are short-lived affective responses caused by the direct environment of an individual (cf. Izard, 1977; Plutchik, 1980). To clarify the different phases involved in an emotional experience, Scherer (2005) distinguishes five main components, including (1) a cognitive component in the form of appraisal, (2) a neurophysiological component, which concerns bodily symptoms, (3) a motivational component that determines action, (4) a motor expression component, and (5) feelings. These phases relate to a single event. A distinction based on valence or activation (Russell, 1980) is useful to provide an overall view of a certain context. For instance, it is insightful to know that, generally speaking, a vacation increases positive emotions (Mitas, Yarnal, Adams et al., 2012), while retaining negative emotions at a stable level (Lin et al., 2014). However, a single event can coactivate multiple emotions of potentially different valence 
and activation (cf. Larsen, Hemenover, Norris, \& Cacioppo, 2003). Therefore, an emotion-specific approach is required, as specific emotions may lead to specific outcomes (Lerner \& Keltner, 2000). An important reason to examine the valence of specific emotions is the broaden and build theory (Fredrickson, 2001, 2004), which explains the long-term quality of life outcomes of frequent positive emotional experiences. Positive emotions have motivational components that are relatively broader than neutral or negative emotions, empowering individuals to build personal resources such as relationships, information, and self-awareness over time. At the same time, negative emotions are themselves adaptive and culturally appropriate in certain contexts.

Nawijn and Fricke (2015) reviewed studies on emotional response at dark tourism sites and conclude that (1) negative emotions dominate the emotional responses reported in visitor studies at dark sites and that (2) visits to dark sites coactivate negative and positive emotional responses. Contrary to a hedonic context, the study at Neuengamme demonstrated that negative emotions explain more of the variance in behavioral intentions than positive emotions (Nawijn \& Fricke, 2015). Their review underlines earlier remarks by Preece and Price (2005) and Walter (2009) that existing studies on tourists' emotions at dark tourism sites are generally descriptive rather than analytical.

\section{Personality}

Personality deals with individual differences in terms of behavior, cognition, and emotion. The current dominant view on personality is that of the FiveFactor Model, also known as the Big Five (McCrae \& Costa, 1991; McCrae \& John, 1992). The Big Five model posits that personality can be organized in five traits, namely openness, conscientiousness, extraversion, agreeableness, and neuroticism (i.e., emotional stability). Personality is highly heritable (Turkheimer \& Waldron, 2000). For instance, twin studies showed that heritability per trait ranges between 42\% and 57\% (Bouchard Jr. \& McGue, 2003). Furthermore, four of the five traits are associated with the volume of particular brain regions (DeYoung et al., 2010), highlighting the biological basis of personality. Personality traits are relatively stable over the life course, particularly for adults (cf. Costa \& McCrae, 1994; Gustavsson, Weinryb, Göransson, Pedersen, \& Åsberg, 1997). Emotions are partially determined by personality traits. For instance, extraversion is generally related to positive emotions, whereas neuroticism is more often associated with negative emotions (Rusting \& Larsen, 1997).

\section{Meaning in Life}

Meaning in life is an often-discussed concept (Baumeister, 1991). The conceptualization of meaning in life is not straightforward and multiple interpretations of the phenomenon exist. This study follows a conceptualization of Davis, Nolen-Hoeksema, and Larson (1998). These authors distinguished two forms of meaning in life. One type reflects the past, in the sense that this type of meaning deals with making sense of what happened. The second type of meaning in life looks more to the future and tries to attach a positive meaning to negative events (Davis et al., 1998). This form of meaning in life is generally defined as "positive meaning." Such positive meaning can be found in times of adversity (cf. Bower et al., 2005; Folkman \& Moskowitz, 2000; Fredrickson, Tugade, Waugh, \& Larkin, 2003) and fits well with the context of this study. A major benefit of finding positive meaning is that it strengthens resilience, which can result in increased well-being over time (Davis et al., 1998). For these reasons, the focus is on this particular aspect of meaning in life in the present study.

Earlier work in the area of dark tourism has found that visits to such places do contribute to finding meaning in life as visits include a confrontation with death, which forces visitors to reflect on their own life and its meaning. For instance, a study of visitors to the Shoah memorial museum in Jerusalem by E. H. Cohen (2011) found that tourists' understanding of the Shoah is enhanced by the museum experience. Similarly, Thurnell-Read (2009) reported that visitors to Auschwitz have a better understanding of the Holocaust because of their visit. Potentially, a visit to a concentration camp memorial also allows visitors to find positive meaning in the sense that their reflections and comparison can contribute to finding positive meaning through their emotional experience. Holocaust 
memorial visits are emotional (Nawijn \& Fricke, 2015), and provide a sense of meaning to tourists (Thurnell-Read, 2009), but the link between emotions and meaning in life remains unexplored. This study addresses this gap in research.

\section{Objective of the Study}

The purpose of this study is to examine how tourists' emotional response to a visit of the Sachsenhausen Memorial and Museum affects finding positive meaning in life and the intention to spread positive word of mouth. Extending previous research on these effects (e.g., Nawijn \& Fricke, 2015), potential effects of personality are controlled for, as personality is intertwined with emotional response and an important interindividual difference for understanding and communicating with different market segments. It is relevant to study emotional response of tourists in a nonhedonic tourism context based on the principle that people tend to avoid pain and seek pleasure. This theoretical assumption of a pleasure-seeking tendency in individuals dates back to the ancient Greeks and has been confirmed empirically in numerous studies (Higgins, 1997). Also in tourism/leisure contexts it is generally accepted-and expected-that a positive consumption experience has positive effects, whereas a negative consumption experience has negative effects (Soscia, 2007). However, this notion is proven to be too simplistic (cf. Higgins, 1997; Lerner \& Keltner, 2000; Zeelenberg et al., 2008). Additionally, emotional involvement is an important reason for people to visit a dark tourism site (Biran et al., 2011). By studying visitor emotions in such a context, it is expected to find that visitors do not only experience pleasure (i.e., positive emotions), but also pain (i.e., negative emotions). Thus, although a visit coactivates pain and pleasure (cf. Nawijn \& Fricke, 2015), a mix of emotions of different valence is expected to be associated with positive word of mouth and an experience that is meaningful to visitors in a positive way.

By using a quantitative approach in the study of emotion and personality, including a contemporary personality scale (Rammstedt \& John, 2007) and an elaborate 24-item emotion scale, this study also represents a different approach compared to earlier work on emotional response in hedonically unpleasant tourism contexts, which used a limited 10-item emotion scale (Nawijn \& Fricke, 2015) or mainly qualitative methods (e.g., Best, 2007; Stone, 2012; Thurnell-Read, 2009). The research questions of this study are: (1) How do tourists' emotional responses explain positive meaning derived from the visit over and above personality? (2) How do tourists' emotional responses explain positive word of mouth over and above personality? (3) Does positive meaning mediate the potential effect of emotions on positive word of mouth?

\section{Methodology}

\section{Study Design and Data Collection}

The data for this study were collected using a self-administered survey questionnaire at the Sachsenhausen Memorial and Museum between March 18, 2014 and March 23, 2014. A nonprobability diversity sampling approach was used. Visitors were approached at the exit of the memorial, which every visitor passes after their visit, and asked to participate in the survey. Data were collected on various days of the week over periods of time lasting 3 to $5 \mathrm{hr}$ to increase the diversity of visitors. Two hundred seventy-nine visitors completed the survey. In terms of nationality, the largest number of respondents was German (27.3\%), with visitors from Spain (13.1\%) and the US (11.2\%) also substantially represented. Gender division was almost equal (52.7\% female; $47.3 \%$ male). The oldest respondent was 80 years old $(M=33.15$; $S D=15.371)$.

\section{Study Instrument}

The self-report questionnaire was created in the English language and translated to German and Spanish. The German version of the questionnaire was translated from English to German by one of the authors, who is a native German speaker. The German version was checked for potential translation issues by three native German speakers and a bilingual speaker. The Spanish version of the questionnaire was translated from English by one of the authors. The Spanish version was checked by two native Spanish speakers and an English-Spanish 
language teacher. Logistical limitations precluded translation into further languages. The choice for English, German, and Spanish questionnaires corresponded with observed language abilities of visitors to the site.

\section{Emotions}

Psychological as well as tourism research on emotions typically uses a list of emotion words that participants are asked to rate based on the intensity of their feelings (e.g., PANAS; Watson, Clark, \& Tellegen, 1988). A single, widely favored scale to measure emotions in a leisure or tourism context does not exist (cf. Buda, d'Hauteserre, \& Johnston, 2014; J. Lee \& Kyle, 2013; Lin et al., 2014). The current study adopts a 24-item emotion scale. Twelve positive emotions were included: awe, contentment, curiosity, fascination, gratitude, hope, interest, joy, love, positive surprise, pride, and respect. Twelve negative emotions were also included: anger, despair, disgust, embarrassment, fear, grief, guilt, horror, negative surprise, sadness, shame, and shock. The choice for these emotions was based on scales used by Nawijn and Fricke (2015) and Lin et al. (2014). Almost all emotion items of these scales were used, with some exceptions based on previous international tourism data collections in which complex emotion words were not understood by respondents (Gillet, Schmitz, \& Mitas, 2013). Respondents indicated the extent to which they had felt each emotion during their visit. Every emotion item was scored on a 5-point scale that ranged from "not at all" (1) to "very strongly" (5).

\section{Personality}

The BFI-10 by Rammstedt and John (2007) was used to measure personality in terms of the Big Five (McCrae \& John, 1992). The BFI-10 is a short version of the BFI-44 and especially designed for research settings with limited time constraints. Lin et al. (2014) used the 10-item personality inventory (TIPI; Gosling, Rentfrow, \& Swann Jr., 2003). The BFI-10 performs better than the TIPI, due to its lower intercorrelations and the clear fivefactor structure. The BFI-10 captures $70 \%$ of the full variance in the BFI-44 and retains $85 \%$ of its retest reliability (Rammstedt \& John, 2007). The BFI-10 was calculated according to instructions by Rammstedt and John (2007). Intercorrelations between the traits were mostly nonsignificant $(p>0.05)$. Small significant intercorrelations were observed between extraversion and neuroticism ( $r=-0.129 ; p=0.041)$, between neuroticism and conscientiousness $(r=-0.127 ; p=0.045)$, and conscientiousness and openness $(r=0.149 ; p=0.019)$. Overall, this implies that the BFI-10 produced valid measures of personality traits.

\section{Positive Word of Mouth}

Positive word of mouth was included as a behavioral intention. Earlier work has also included revisit intention (Nawijn \& Fricke, 2015). Revisit intention was excluded from the present article as revisit intention is generally low for concentration camp memorials, thus not necessarily related to the visitor experience. Furthermore, revisit intention corresponds only weakly to actual behavior (McKercher \& Tse, 2012). Positive word of mouth was scored on a 5-point scale that ranged from "strongly disagree" (1) to "strongly agree" (5).

\section{Positive Meaning in Life}

Three items that comprised positive meaning in life were derived from a study by Fredrickson et al. (2003). The items were "I feel I will have a positive benefit from my visit"; "I think that there is something to learn from my visit"; and "I can find positive meaning in my visit.” These items used a 5-point scale ( $1=$ strongly disagree; 5 = strongly agree). Cronbach's alpha for positive meaning in life (0.834) indicated good internal consistency and reliability (Cortina, 1993). A positive meaning in life variable was created by calculating the mean score of these three items.

\section{Data Screening and Analysis}

The emotion items, positive meaning in life items, and positive word of mouth were screened for severely incomplete responses. Nineteen questionnaires were omitted as more than half of responses to these key items on the questionnaire were missing. Thus, the final sample comprised 260 visitors. 
It is imperative to study emotions individually rather than in an aggregated manner, especially given the specific nonhedonic context of the study. In other words, emotions in this study are considered observed variables rather than latent factors. This makes sense theoretically, but to verify this assumption empirically, an exploratory factor analysis in SPSS version 21 was performed, followed by a confirmatory factor analysis in AMOS version 22. As some correlation between the emotions was to be expected, the oblique Promax rotation technique was used. Due to issues such as cross-loadings, low communalities, and not loading on a factor, 15 emotions were removed. The exploratory factor analysis finally resulted in a two-factor solution, which explained $45.538 \%$ of the variance. One factor contained four emotions, whereas the other factor contained five emotions. The emotions in the first factor were horror, sadness, shock, and grief. The emotions in the second factor were shame, embarrassment, guilt, anger, and fear. The KMO score of 0.834 was good and Bartlett's test was significant. The factor loadings in the final model were acceptable, but the model had three emotions with factor loadings below 0.5 and the average factor loading on factor 2 did not exceed the preferred average of 0.7. The internal consistencies in terms of Cronbach's alphas were good (0.809) and acceptable (0.754), respectively. The confirmatory factor analysis showed issues of common method bias, which could only be solved by removing embarrassment. However, this did not resolve the common method bias issue. On the contrary, it led to a covariance matrix that was not positive definite. This particular issue could not be resolved and consequently the initial factor model, as exposed via the exploratory factor analysis, could not be confirmed via confirmatory factor analysis.

The first research question ('How do tourists' emotional responses explain positive meaning derived from the visit over and above personality?") was answered by performing a regression analysis on positive meaning in which all 24 emotions were added in Step 2, controlling for personality in Step 1. Effect sizes were interpreted according to guidelines proposed by J. Cohen (1988). Missing values were excluded list wise. The second research question ('How do tourists' emotional responses explain positive word of mouth over and above personality?”) was tested by performing a linear regression analysis in the same way, with positive word of mouth included in the first step (Step 1). Finally, the analysis checked whether positive meaning mediated the potential effect of emotional responses on positive word of mouth, which tackled the third research question ("Does positive meaning mediate the potential effect of emotions on positive word of mouth?”). This potential mediation was tested via a path model that tested direct and indirect effects of emotions on positive word of mouth, potentially mediated by positive meaning in life. To this end, a path model in AMOS version 22 was used.

\section{Results}

Visitors feel interest $(M=4.24, S D=0.791)$, sadness $(M=4.10, S D=1.022)$, horror $(M=3.93$, $S D=1.088)$, and disgust $(M=3.90, S D=1.159)$ the most intensely during their visit to Sachsenhausen Memorial and Museum. Felt least intensely are joy $(M=1.26, S D=0.701)$, pride $(M=1.30$, $S D=0.768)$, contentment $(M=1.73, S D=1.052)$, and love $(M=1.75, S D=1.168)$. Negative emotions are felt more intensely $(M=3.22, S D=0.776)$ than positive emotions $(M=2.45, S D=0.585)$. An overview of all mean scores and standard deviations is presented in Table 1.

The visitors in the sample are generally quite willing to spread positive word of mouth $(M=4.41$; $S D=0.850)$. Positive meaning in life is also relatively high $(M=4.16 ; S D=0.834)$.

The first research question was answered by performing a regression analysis with positive meaning. The personality traits were entered in Step 1 as controls. All emotions were added in Step 2. The findings are presented in Table 2. The model was significant as a whole. Of the total variance in positive meaning, $31.2 \%$ was explained by the model, $F(29,143)=2.234, p<0.005$.

Contentment $(\beta=-0.230, p=0.014)$, positive surprise $(\beta=0.189, p=0.023)$, and interest $(\beta=$ 0.307, $p=0.000$ ) contributed significantly to the explained variance in positive meaning. The emotions explained $25.0 \%$ of the variance in positive meaning. The personality traits explained $6.2 \%$ of the variance in positive meaning. Conscientiousness 
Table 1

Tourists’ Emotional Response to Sachsenhausen

\begin{tabular}{lcc}
\hline Emotion & $M$ & $S D$ \\
\hline Interest & 4.24 & 0.791 \\
Sadness & 4.10 & 1.022 \\
Horror & 3.93 & 1.088 \\
Disgust & 3.90 & 1.159 \\
Curiosity & 3.57 & 1.049 \\
Shock & 3.48 & 1.159 \\
Anger & 3.45 & 1.244 \\
Grief & 3.42 & 1.237 \\
Respect & 3.28 & 1.491 \\
Shame & 3.08 & 1.458 \\
Negative surprise & 3.00 & 1.285 \\
Awe & 2.97 & 1.346 \\
Despair & 2.94 & 1.262 \\
Fascination & 2.82 & 1.355 \\
Fear & 2.73 & 1.296 \\
Hope & 2.39 & 1.242 \\
Embarrassment & 2.39 & 1.356 \\
Guilt & 2.13 & 1.245 \\
Gratitude & 2.01 & 1.244 \\
Positive surprise & 1.99 & 1.177 \\
Love & 1.75 & 1.168 \\
Contentment & 1.73 & 1.052 \\
Pride & 1.30 & 0.768 \\
Joy & 1.26 & 0.701 \\
\hline
\end{tabular}

is associated with positive meaning and with horror, shame, and joy. These emotions do not make an individual contribution in the explained variance of positive meaning in the regression analysis.

To answer the second research question, a regression analysis with positive word of mouth was performed. The personality traits were entered in Step 1, as control variables. In the following step, all emotions were added. The findings on positive word of mouth are presented in Table 3 . The model was significant as a whole. The total variance explained in positive word of mouth was $32.8 \%$, $F(29,143)=2.403, p<0.0001$.

Shock and interest contribute significantly to the explained variance in positive word of mouth. Shock lowers positive word of mouth $(\beta=-0.289$, $p=0.010$ ), whereas interest raises positive word of mouth $(\beta=0.329, p=0.000)$. The emotions explained $28.5 \%$ of the variance in positive word of mouth. The personality traits explained approximately only $4 \%$ of the variance.

Finally, the analysis ended with a test of whether finding positive meaning in life mediates the effect
Table 2

Regression for Positive Meaning With Emotions, Controlled for Personality Traits

\begin{tabular}{|c|c|c|c|}
\hline Variable & $\beta$ & Sig. & $R^{2}$ Change \\
\hline Extraversion & & 0.429 & 0.062 \\
\hline Agreeableness & & 0.546 & \\
\hline Conscientiousness & & 0.337 & \\
\hline Neuroticism & & 0.709 & \\
\hline Openness & & 0.640 & \\
\hline Awe & & 0.422 & 0.250 \\
\hline Contentment & -0.230 & 0.014 & \\
\hline Curiosity & & 0.942 & \\
\hline Fascination & & 0.684 & \\
\hline Gratitude & & 0.836 & \\
\hline Hope & & 0.737 & \\
\hline Interest & 0.307 & 0.000 & \\
\hline Joy & & 0.356 & \\
\hline Love & & 0.873 & \\
\hline Positive surprise & 0.189 & 0.023 & \\
\hline Pride & & 0.064 & \\
\hline Respect & & 0.207 & \\
\hline Anger & & 0.262 & \\
\hline Despair & & 0.417 & \\
\hline Disgust & & 0.569 & \\
\hline Embarrassment & & 0.793 & \\
\hline Fear & & 0.933 & \\
\hline Grief & & 0.289 & \\
\hline Guilt & & 0.812 & \\
\hline Horror & & 0.981 & \\
\hline Negative surprise & & 0.295 & \\
\hline Sadness & & 0.419 & \\
\hline Shame & & 0.787 & \\
\hline Shock & & 0.463 & \\
\hline
\end{tabular}

Note. Total $R^{2}=0.312, F=2.234$. Reported betas are standardized; $R^{2}$ change indicated per Step.

of emotions on positive word of mouth. In AMOS version 22, a path model was created using the emotions that have significant $(p<0.05)$ zero-order correlations with positive word of mouth. These are: awe, curiosity, hope, interest, positive surprise, respect, anger, disgust, horror, sadness, shame. The path model indicated that its fit was poor (e.g., $\mathrm{CFI}=0.185$; $\mathrm{RMSEA}=0.186$ ) and that there was no mediation effect. The indirect effects, in terms of the standardized regression coefficients, were all close to zero. The highest observed indirect effect was only 0.04 . The direct effects were similar to those observed in the regression analyses. Therefore, it is safe to say that there was no mediation effect of positive meaning. Consequently, positive word of mouth and positive meaning should be regarded as separate outcome variables. 
Table 3

Regression for Positive Word of Mouth With Emotions, Controlled for Personality Traits

\begin{tabular}{|c|c|c|c|}
\hline Variable & $\beta$ & Sig. & $R^{2}$ Change \\
\hline Extraversion & & 0.724 & 0.042 \\
\hline Agreeableness & & 0.607 & \\
\hline Conscientiousness & & 0.511 & \\
\hline Neuroticism & & 0.409 & \\
\hline Openness & & 0.993 & \\
\hline Awe & & 0.106 & 0.285 \\
\hline Contentment & & 0.423 & \\
\hline Curiosity & & 0.755 & \\
\hline Fascination & & 0.252 & \\
\hline Gratitude & & 0.302 & \\
\hline Hope & & 0.177 & \\
\hline Interest & 0.329 & 0.000 & \\
\hline Joy & & 0.843 & \\
\hline Love & & 0.802 & \\
\hline Positive surprise & & 0.051 & \\
\hline Pride & & 0.325 & \\
\hline Respect & & 0.586 & \\
\hline Anger & & 0.055 & \\
\hline Despair & & 0.222 & \\
\hline Disgust & & 0.118 & \\
\hline Embarrassment & & 0.620 & \\
\hline Fear & & 0.962 & \\
\hline Grief & & 0.950 & \\
\hline Guilt & & 0.919 & \\
\hline Horror & & 0.921 & \\
\hline Negative surprise & & 0.774 & \\
\hline Sadness & & 0.054 & \\
\hline Shame & & 0.618 & \\
\hline Shock & -0.289 & 0.010 & \\
\hline
\end{tabular}

Note. Total $R^{2}=0.328, F=2.403$. Reported betas are standardized; $R^{2}$ change indicated per Step.

\section{Conclusion and Discussion}

The purpose of this study was to examine how visitors' emotional response to a visit of the Sachsenhausen Memorial and Museum affects finding positive meaning in life and the intention to spread positive word of mouth. Although emotional response explained between $25 \%$ and $28.5 \%$ in the variance in behavioral intentions and positive meaning, the personality traits explained only between $4.2 \%$ and $6.2 \%$. Thus, the findings indicate that personality traits have hardly any effect on the consequences of the visit, in terms of finding positive meaning in life and spreading positive word of mouth.

The importance of emotion over personality in the consequences of the visit extend existing literature in multiple ways. First, some authors have asserted that a certain "type" of person could be more attracted to or affected by dark tourism experiences such as Sachsenhausen (e.g., Wight, 2006). In contrast, the findings suggest that the experience at the site, specifically in terms of emotions, may be more powerful than stable interindividual differences, such as personality. Second, research on hedonic vacations suggests that tourists' personality can be an important determinant of emotional response (Lin et al., 2014). This study's findings suggest that-in terms of finding positive meaning in life- the role of personality is rather limited in nonhedonic contexts.

The emotion of interest is of particular importance. Interest raises the extent to which visitors find positive meaning through the visit and increases the likelihood of spreading positive word of mouth. Interest, an emotion sparked by novelty (Fredrickson, 1998), has been said to be the most common or even "default" human emotion (Izard, 1977). Foundational studies asserted that tourism experiences are generally marked by modulated pursuit of novelty (e.g., Crompton, 1979), likely leading to feelings of interest across a variety of tourism experiences, such as brief outings focused on participants' hobbies or passions (Mitas, Yarnal, \& Chick, 2012). The sample's experiences of Sachsenhausen suggest that, despite a different balance of positive to negative emotions, interest is at least as prominent in a dark tourism experience as in some hedonic types of trips.

The finding that negative emotions dominate the visitor experience is consistent with that of Nawijn and Fricke (2015) and Brown (2015), and conceptual work on visitor experiences at dark tourism sites (Stone \& Sharpley, 2008). Although "negative" emotions are experienced more intensely on average, "positive" emotions contribute individually to the explained variance in finding positive meaning. Interest and positive surprise have a positive effect, whereas contentment has a negative effect on finding positive meaning in life.

These findings extend the work on the tourist experience at concentration camp memorials by showing that, despite a dominant negative emotional response, tourists find positive meaning in their visit. The results match those observed in studies on personal trauma and loss, showing that effort in the form of cognitive framing (e.g., what happened was horrible, but we can learn from it to become better people) leads to positive long-term 
outcomes from intensely negative emotional experiences (e.g., Bower et al., 2005; Davis et al., 1998).

The findings also partly contest the pleasure principle, which assumes that individuals simply seek pleasure and avoid pain (cf. Higgins, 1997). Even though the traumatic event that tourists are confronted with in this context may not necessarily be of a personal nature, finding positive meaning can potentially contribute to adjustment processes to cope with what happened, which in turn may lead to increased well-being over time (Davis et al., 1998).

Additionally, the findings reveal that emotional response contributes to finding positive meaning derived from the visit. This partly supports the broaden and build theory of positive emotions (Fredrickson, 2001, 2004) in the sense that certain positive emotions-mainly interest-contribute to finding positive meaning. However, contentment lowers positive meaning. This contrasts theoretical assumptions of the broaden and build theory on the supposed universal positivity of positive emotions. Similarly, the factor analyses underscore the assertion of the importance of distinguishing between unique emotions (Lerner \& Keltner, 2000; Zeelenberg et al., 2008), specifically in tourism contexts (Mitas, Yarnal, Adams, et al., 2012), and according to this study, particularly in specific dark tourism contexts.

\section{Limitations and Suggestions for Future Research}

This study included an elaborate 24-item emotion scale. However, more emotions exist than the ones that are included (cf. Lin et al., 2014). A truly exhaustive list may have been too long to use in an on-site survey. Therefore, future research should aim to develop a feasible emotion scale grounded in current psychological theory that can be used in multiple tourism contexts.

Positive word of mouth is very important for Holocaust memorials, as the available budgets are generally tight and aggressive promotion is ethically questioned. Raising interest and lowering shock are important for positive word of mouth to be successful. Concentration camp memorials would thus benefit from assessing what exactly triggers interest and shock and carefully design their tours in such a way that interest is raised and shock is lowered (cf. Pullman \& Gross, 2004). More generally, just as scientific research of tourists' emotions should distinguish between specific emotions, it is important for destinations and attractions to measure and manage for specific emotions, as each emotion has a unique set of causes and consequences. The findings support this approach in the context of dark tourism sites.

Furthermore, the explained variances that were observed for positive meaning and positive word of mouth were somewhat low, namely $31.2 \%$ and $32.8 \%$, respectively. Likely cognitions such as attitudes or beliefs explain part of the variance, which could not be uncovered in this study (cf. Y.-J. Lee, 2016). Therefore, future studies should include both affective and cognitive measures.

Additionally, the focal point of meaning in this study is that of positive meaning in terms of benefit finding. Another construal of meaning deals with making sense of what happened. According to Davis et al. (1998), this is a different type of meaning that likely involves a different psychological process. This type of meaning is associated with less distress (Davis et al., 1998). In this study's context, this could be related to negative emotions experienced on site. Future research would be required to test this assumption.

Also, the findings of this study pose an interesting question for future research, namely if visitors to dark tourism sites are aware of the observed long-term outcomes. It is also important to assess whether they see their visit as an unpleasant but ultimately beneficial investment in their future, or, in contrast, are unaware of the potential long-term impact of their visit.

Finally, although personality traits are controlled for in the analyses, there is the possibility of an unknown third variable effect. Longitudinal research would be needed to clearly distinguish between cause and effect.

\section{References}

Baumeister, R. F. (1991). Meanings of life. New York: The Guilford Press.

Best, M. (2007). Norfolk Islands: Thanatourism, history and visitor emotions. Shima: The International Journal of Research into Island Cultures, 1(2), 30-48.

Bigné, J. E., Andreu, L., \& Gnoth, J. (2005). The theme park experience: An analysis of pleasure, arousal and satisfaction. Tourism Management, 26(6), 833-844. doi: 10.1016/j.tourman.2004.05.006

Biran, A., Poria, Y., \& Oren, G. (2011). Sought experiences at (dark) heritage sites. Annals of Tourism Research, 38(3), 820-841. doi: 10.1016/j.annals.2010.12.001 
Bouchard Jr., T. J., \& McGue, M. (2003). Genetic and environmental influences on human psychological differences. Journal of Neurobiology, 54(1), 4-45. doi: 10.1002/neu.10160

Bower, J. E., Meyerowitz, B. E., Bernaards, C. A., Rowland, J. H., Ganz, P. A., \& Desmond, K. A. (2005). Perceptions of positive meaning and vulnerability following breast cancer: Predictors and outcomes among long-term breast cancer survivors. Annals of Behavioral Medicine, 29(3), 236-245. doi: 10.1207/s15324796abm2903_10

Brown, L. (2015). Memorials to the victims of Nazism: The impact on tourists in Berlin. Journal of Tourism and Cultural Change, 13(3), 244-260. doi: 10.1080/14766825. 2014.946423

Buda, D. M., d'Hauteserre, A.-M., \& Johnston, L. (2014). Feeling and tourism studies. Annals of Tourism Research, 46, 102-114. doi: 10.1016/j.annals.2014.03.005

Cohen, E. H. (2011). Educational dark tourism at an in populo site: The Holocaust Museum in Jerusalem. Annals of Tourism Research, 38(1), 193-209. doi: 10.1016/ j.annals.2010.08.003

Cohen, J. (1988). Statistical power analysis for the behavioral sciences (2nd ed.). Hillsdale, NJ: Lawrence Earlbaum Associates.

Cortina, J. M. (1993). What is coefficient alpha? An examination of theory and applications. Journal of Applied Psychology, 78(1), 98-104. doi: 10.1037/0021-9010. 78.1 .98

Costa, P. T., \& McCrae, R. R. (1994). Set like plaster? Evidence for the stability of adult personality. In T. F. Heatherton \& J. L. Weinberger (Eds.), Can personality change? (pp. 21-40). Washington, DC: American Psychological Association Books.

Crompton, J. L. (1979). Motivations for pleasure vacation. Annals of Tourism Research, 6(4), 408-424. doi: 10. 1016/0160-7383(79)90004-5

Davis, C. G., Nolen-Hoeksema, S., \& Larson, J. (1998). Making sense of loss and benefiting from the experience: Two construals of meaning. Journal of Personality and Social Psychology, 75(2), 561-574. doi: 10.1037/00223514.75.2.561

DeYoung, C. G., Hirsh, J. B., Shane, M. S., Papademetris, X., Rajeevan, N., \& Gray, J. R. (2010). Testing predictions from personality neuroscience. Brain structure and the Big Five. Psychological Science, 21(6), 820-828. doi: $10.1177 / 0956797610370159$

Farmer, S. (1995). Symbols that face two ways: Commemorating the victims of Nazism and Stalinism at Buchenwald and Sachsenhausen. Representations, 49, 97-119.

Folkman, S., \& Moskowitz, J. T. (2000). Positive affect and the other side of coping. American Psychologist, 55(6), 647-654. doi: 10.1037/0003-066X.55.6.647

Fredrickson, B. L. (1998). What good are positive emotions? Review of General Psychology, 2(3), 300-319. doi: 10.1037/1089-2680.2.3.300

Fredrickson, B. L. (2001). The role of positive emotions in positive psychology: The broaden-and-build theory of positive emotions. American Psychologist, 56(3), 218-226. doi: 10.1037/0003-066X.56.3.218

Fredrickson, B. L. (2004). The broaden-and-build theory of positive emotions. Philosophical Transactions of the Royal Society of London Series B-Biological Sciences, 359(1449), 1367-1377. doi: 10.1098/rstb.2004.1512

Fredrickson, B. L., Tugade, M., Waugh, C. E., \& Larkin, G. R. (2003). What good are positive emotions in crises? A prospective study of resilience and emotions following the terrorist attacks on the United States on September 11th, 2001. Journal of Personality and Social Psychology, 84(2), 365-376. doi: 10.1037/0022-3514.84.2.365

Gilbert, D., \& Abdullah, J. (2004). Holidaytaking and the sense of well-being. Annals of Tourism Research, 31(1), 103-121. doi: 10.1016/j.annals.2003.06.001

Gillet, S., Schmitz, P., \& Mitas, O. (2013). The snap-happy tourist: The effects of photographing behavior on tourists' happiness. Journal of Hospitality \& Tourism Research, 40(1), 37-57. doi: 10.1177/1096348013491606

Gosling, S. D., Rentfrow, P. J., \& Swann Jr., W. B. (2003). A very brief measure of the Big-Five personality domains. Journal of Research in Personality, 37(6), 504-528. doi: 10.1016/S0092-6566(03)00046-1

Gustavsson, J. P., Weinryb, R. M., Göransson, S., Pedersen, N. L., \& Åsberg, M. (1997). Stability and predictive ability of personality traits across 9 years. Personality and Individual Differences, 22(6), 783-792.

Higgins, E. T. (1997). Beyond pleasure and pain. American Psychologist, 52(12), 1280-1300. doi: 10.1037/0003066X.52.12.1280

Hosany, S., \& Gilbert, D. (2010). Measuring tourists' emotional experiences toward hedonic holiday destinations. Journal of Travel Research, 49(4), 513-526. doi: 10.1177/0047287509349267

Isaac, R. K., \& Çakmak, E. (2014). Understanding visitor's motivation at sites of death and disaster: The case of former transit camp Westerbork, the Netherlands. Current Issues in Tourism, 17(2), 164-179. doi: 10.1080/13683500.2013.776021

Izard, C. E. (1977). Human emotions. New York, NY: Plenum Press.

Larsen, J. T., Hemenover, S. H., Norris, C. J., \& Cacioppo, J. T. (2003). Turning adversity to advantage: On the virtues of the coactivation of positive and negative emotions. In L. G. Aspinwall \& U. M. Staudinger (Eds.), A psychology of human strengths: Perspectives on an emerging field (pp. 211-225). Washington, DC: American Psychological Association.

Lee, J., \& Kyle, G. T. (2013). The measurement of emotions elicited within festival contexts: A psychometric test of a festival consumption emotions (FCE) scale. Tourism Analysis, 18(6), 635-649. doi: 10.3727/108354213X13 824558188541

Lee, Y.-J. (2016). The relationship amongst emotional experience, cognition, and behavioral intention in battlefield tourism. Asia Pacific Journal of Tourism Research, 21(6), 697-715. doi: 10.1080/10941665.2015.1068195 
Lerner, J. S., \& Keltner, D. (2000). Beyond valence: Toward a model of emotion-specific influences on judgement and choice. Cognition \& Emotion, 14(5), 473-493. doi: 10.1080/026999300402763

Lin, Y., Kerstetter, D., Nawijn, J., \& Mitas, O. (2014). Changes in emotions and their interaction with personality in a vacation context. Tourism Management, 40, 416-424. doi: 10.1016/j.tourman.2013.07.013

McCrae, R. R., \& Costa, P. T. (1991). Adding liebe und arbeit: The full five-factor model and well-being. Personality and Social Psychology Bulletin, 17(2), 227-232. doi: 10.1177/014616729101700217

McCrae, R. R., \& John, O. P. (1992). An introduction to the five-factor model and its applications. Journal of Personality, 60(2), 175-215. doi: 10.1111/j.1467-6494.1992. tb00970.x

McKercher, B., \& Tse, T. S. M. (2012). Is intention to return a valid proxy for actual repeat visitation? Journal of Travel Research, 51(6), 671-686. doi: 10.1177/0047287 512451140

Memorial and Museum Sachsenhausen. (2014). Sachsenhausen concentration camp 1936-1945. Retrieved from http://www.stiftung-bg.de/gums/en/index.htm?sess=b24 26e6704eeb4036ec6d830e38c17f9

Mitas, O., Yarnal, C., Adams, R., \& Ram, N. (2012). Taking a "peak" at leisure travelers' positive emotions. Leisure Sciences, 34(2), 115-135. doi: 10.1080/01490400. 2012.652503

Mitas, O., Yarnal, C., \& Chick, G. (2012). Jokes build community: Mature tourists' positive emotions. Annals of Tourism Research, 39(4), 1884-1905. doi: 10.1016/j. annals.2012.05.003

Nawijn, J. (2011). Determinants of daily happiness on vacation. Journal of Travel Research, 50(5), 559-566. doi: 10.1177/0047287510379164

Nawijn, J., \& Damen, Y. (2014). Work during vacation: Not so bad after all. Tourism Analysis, 19(6), 759-767. doi: 10. 3727/108354214X14146846679565

Nawijn, J., \& Fricke, M.-C. (2015). Visitor emotions and behavioral intentions: The case of concentration camp memorial Neuengamme. International Journal of Tourism Research, 17(3), 221-228. doi: 10.1002/jtr.1977

Nawijn, J., Isaac, R. K., Gridnevskiy, K., \& Van Liempt, A. (2015). Holocaust concentration camp memorial sites: An exploratory study into expected emotional response. Current Issues in Tourism, online ahead of print. doi: 10.1080/13683500.2015.1058343

Pearce, P. L. (1981). “Environment shock”: A study of tourists' reactions to two tropical islands. Journal of Applied Social Psychology, 11(3), 268-280. doi: 10.1111/j.15591816.1981.tb00744.x

Plutchik, R. (1980). Emotion: A psychoevolutionary synthesis. New York, NY: Harper and Row.

Preece, T., \& Price, G. (2005). Motivations of participants in dark tourism: A Port Arthur example. In C. Ryan, S. Page, \& M. Aicken (Eds.), Taking tourism to the limits (pp. 17-28). Oxford, UK: Elsevier.
Pullman, M. E., \& Gross, M. A. (2004). Ability of experience design elements to elicit emotions and loyalty behaviors. Decision Sciences, 35(3), 551-578. doi: 10.1111/j.00117315.2004.02611.x

Rammstedt, B., \& John, O. P. (2007). Measuring personality in one minute or less: A 10-item short version of the Big Five inventory in English and German. Journal of Research in Personality, 41(1), 203-212. doi: 10.1016/j. jrp.2006.02.001

Russell, J. A. (1980). A circumplex model of affect. Journal of Personality and Social Psychology, 39(6), 1161-1178. doi: 10.1037/h0077714

Rusting, C. L., \& Larsen, R. J. (1997). Extraversion, neuroticism, and susceptibility to positive and negative affect: A test of two theoretical models. Personality and Individual Differences, 22(5), 607-612. doi: 10.1016/S01918869(96)00246-2

Scherer, K. R. (2005). What are emotions? And how can they be measured? Social Science Information, 44(4), 695-729. doi: 10.1177/0539018405058216

Soscia, I. (2007). Gratitude, delight, or guilt: The role of consumers' emotions in predicting postconsumption behaviors. Psychology \& Marketing, 24(10), 871-894. doi: 10.1002/mar.20188

Stone, P. R. (2012). Dark tourism as "mortality capital”: The case of Ground Zero and the significant other dead. In R. Sharpley \& P. R. Stone (Eds.), Contemporary tourist experience: Concepts and consequences (pp. 71-94). Abingdon, UK: Routledge.

Stone, P. R., \& Sharpley, R. (2008). Consuming dark tourism: Athanatological perspective. Annals of Tourism Research, 35(2), 574-595. doi: 10.1016/j.annals.2008.02.003

Thurnell-Read, T. P. (2009). Engaging Auschwitz: An analysis of young travellers' experiences of holocaust tourism. Journal of Tourism Consumption and Practice, 1(1), 26-52.

Turkheimer, E., \& Waldron, M. (2000). Nonshared environment: A Theoretical, methodological, and quantitative review. Psychological Bulletin, 126(1), 78-108. doi: 10.1037/0033-2909.126.1.78

Walter, T. (2009). Dark tourism: Mediating between the dead and the living. In R. Sharpley \& P. R. Stone (Eds.), The darker side of travel: The theory and practice of dark tourism (pp. 39-55). Bristol, UK: Channel View Publications.

Watson, D., Clark, L. A., \& Tellegen, A. (1988). Development and validation of brief measures of positive and negative affect: The panas scales. Journal of Personality and Social Psychology, 54(6), 1063-1070. doi: 10.1037/0022-3514.54.6.1063

Wight, A. C. (2006). Philosophical and methodological praxes in dark tourism: Controversy, contention and the evolving paradigm. Journal of Vacation Marketing, 12(2), 119-129. doi: 10.1177/1356766706062151

Zeelenberg, M., Nelissen, R., Breugelmans, S. M., \& Pieters, R. (2008). On emotion specificity in decision making: Why feeling is for doing. Judgment and Decision Making, 3(1), 18-27. 